\title{
EVALUACIÓN DEL RIESGO AMBIENTAL DEL INSECTICIDA METAMIDOFOS EN BIOENSAYOS CON CUATRO ORGANISMOS ACUÁTICOS NO DESTINATARIOS
}

\author{
Environmental risk assessment of the insecticide metamidophos in bioassays \\ with four non-target aquatic organisms
}

\author{
José Iannacone O. ${ }^{1,2}$ *, Roxana Onofre C. ${ }^{2}$, Olga Huanqui S. ${ }^{2}$, Jorge Giraldo A. ${ }^{2}$, \\ Nancy Mamani P. ${ }^{3}$, María C. Miglio T. ${ }^{3}$ y Lorena Alvariño F. ${ }^{2}$
}

A B S T R A C T

The aim of this research was to evaluate the ecotoxicological effect of methamidophos using two formulations of different toxicological class [Monofos ${ }^{\circledR}$, class Ia (extremely dangerous) and Tamaron $\mathbb{R}$, class Ib (highly dangerous)] on four non-target aquatic organisms: bloodworm Chironomus calligraphus (Goeldi, 1905) (Diptera: Chironomidae), black sea urchin Tetrapygus niger Molina, 1782 (Echinodermata: Arbaciidae), neon tetra Paracheirodon innesi (Rabout, 1940) (Osteichthyes: Characidae), and rainbow trout Oncorhynchus mykiss (Walbaum, 1792) (Osteichthyes: Salmonidae). Both methamidophos formulations evidenced a high risk effect on the aquatic environment, finding effects on larvae of $C$. calligraphus (Class Ia, $\mathrm{LC}_{50}$ at $48 \mathrm{~h}=1.32 \mathrm{mg}$ a.i. $\mathrm{L}^{-1}$ and Class $\mathrm{Ib}, \mathrm{LC}_{50}$ at $48 \mathrm{~h}=4.5 \mathrm{mg}$ a.i. $\left.\mathrm{L}^{-1}\right)$, on fertilization of $T$. niger (Class $\mathrm{Ia}_{1} \mathrm{IC}_{50}$ at $1 \mathrm{~h}=1423 \mathrm{mg}$ a.i. $\mathrm{L}^{-1}$ and Class $\mathrm{Ib}, \mathrm{IC}_{50}$ at $1 \mathrm{~h}=608 \mathrm{mg}$ a.i. $\mathrm{L}^{-1}$ ), on P. innesi (Class Ia, $\mathrm{LC}_{50}$ at $96 \mathrm{~h}=20.56 \mathrm{mg}$ a.i. $\mathrm{L}^{-1}$ and Class $\mathrm{Ib}, \mathrm{LC}_{50}$ at 96 $\mathrm{h}=10.13 \mathrm{mg}$ a.i. $\mathrm{L}^{-1}$ ) and $O$. mykiss (Class $\mathrm{Ib}, \mathrm{LC}_{50}$ at $96 \mathrm{~h}=19.12 \mathrm{mg}$ a.i. $\mathrm{L}^{-1}$ ). The sequence of sensibility to methamidophos in both formulations was: C. calligraphus $>O$. mykiss $\approx P$. innesi $>T$. niger. In addition, two sublethal effects were evaluated on $P$. innesi, immobilization and strange swimming, and finally an increment of opercular movement in $O$. mykiss. Risk quotients (RQ) indicated in all cases a high risk of methamidophos towards the aquatic environments.

Key words: Chironomus calligraphus, Oncorhynchus mykiss, Paracheirodon innesi, Tetrapygus niger, ecotoxicology, methamidophos.

\section{R E S U M E N}

El objetivo de este trabajo fue evaluar el efecto ecotoxicológico del metamidofos, en dos formulaciones de diferente categoría toxicológica [Monofos ${ }^{\circledR}$, categoría Ia (extremadamente peligroso) y Tamaron ${ }^{\circledR}$, categoría Ib (altamente peligroso)] sobre cuatro organismos acuáticos no destinatarios: la lombriz roja Chironomus calligraphus (Goeldi, 1905) (Diptera: Chironomidae), el erizo negro Tetrapygus niger Molina, 1782 (Echinodermata: Arbaciidae), el neón tetra Paracheirodon innesi (Rabout, 1940) (Osteichthyes: Characidae) y la trucha Oncorhynchus mykiss (Walbaum, 1792) (Osteichthyes: Salmonidae). Ambas formulaciones del metamidofos provocaron un alto riesgo sobre el ambiente acuático, al encontrarse efectos sobre las larvas de $C$. calligraphus (Clase Ia, $\mathrm{CL}_{50}$ a $48 \mathrm{~h}=1,32 \mathrm{mg}$ i.a. $\mathrm{L}^{-1}$ y Clase $\mathrm{Ib}, \mathrm{CL}_{50}$ a $48 \mathrm{~h}=4,5$ $\mathrm{mg}$ i.a. $\mathrm{L}^{-1}$ ), sobre la fertilización de $T$. niger (Class Ia, $\mathrm{CI}_{50}$ a $1 \mathrm{~h}=1423 \mathrm{mg}$ i.a. $\mathrm{L}^{-1}$ y Clase Ib, $\mathrm{CI}_{50}$ a $1 \mathrm{~h}=$ $608 \mathrm{mg}$ i.a. $\mathrm{L}^{-1}$ ), en $P$. innesi (Clase $\mathrm{Ia}, \mathrm{CL}_{50}$ a $96 \mathrm{~h}=$ $20,56 \mathrm{mg}$ i.a. $\mathrm{L}^{-1}$ y Clase $\mathrm{Ib}, \mathrm{CL}_{50}$ a $96 \mathrm{~h}=10,13 \mathrm{mg}$ i.a. $\mathrm{L}^{-1}$ ) y en $O$. mykiss (Clase $\mathrm{Ib}, \mathrm{CL}_{50}$ a $96 \mathrm{~h}=19,12$ mg i.a. $\mathrm{L}^{-1}$ ). La secuencia de sensibilidad al metamidofos en ambas formulaciones fue: C. calligraphus $>$ $O$. mykiss $\approx P$. innesi $>T$. niger. En adición, se evaluaron dos efectos subletales en $P$. innesi, inmovilización y nado extraño, y finalmente, incremento de movimiento opercular en $O$. mykiss. Los cuocientes de riesgo $(\mathrm{CR})$ indicaron en todos los casos un alto riesgo del metamidofos en el ambiente acuático.

Palabras clave: Chironomus calligraphus, Oncorhynchus mykiss, Paracheirodon innesi, Tetrapygus niger, ecotoxicología, metamidofos.

\footnotetext{
${ }^{1}$ Universidad Ricardo Palma (URP), Facultad de Ciencias Biológicas, Av. Benavides 5440, Santiago de Surco, Lima 33, Perú. E-mail: joseiannacone@yahoo.es *Autor para correspondencia.

${ }^{2}$ Universidad Nacional Federico Villarreal (UNFV), Facultad de Ciencias Naturales y Matemática, Calle San Marcos 351, Pueblo Libre, Perú. ${ }^{3}$ Universidad Nacional Agraria La Molina (UNALM), Facultad de Pesquería, Av. La Molina s/n, Apartado 12-056, Lima 12, Perú. Recibido: 17 de marzo de 2006. Aceptado: 25 de mayo de 2006.
} 


\section{INTRODUCCIÓN}

El insecticida organofosforado metamidofos es un acaricida de acción sistémica, de contacto y con alto poder residual (Wu et al., 2001; Hernández et al., 2002; Ismail et al., 2002). Es altamente tóxico para el hombre por vía oral, dérmica y por inhalación (Sosa-Gomez et al., 2001; Evaristo y Baptista, 2002; He et al., 2002; Bouchard et al., 2006). Es un insecticida de amplio espectro para el control de plagas agrícolas que atacan a cultivos como el maíz, papa, brócoli, vid y algodón (Prieto et al., 2002; White et al., 2006). Es uno de los plaguicidas más empleados en la agricultura peruana y del neotrópico, bajo diferentes formulaciones (Iannacone et al., 2002a; Stoorvogel et al., 2003; Recena et al., 2006).

En el Perú, existen 27 productos comerciales y en diferentes formulaciones para el metamidofos en la categoría Ia y Ib registrados en el Servicio Nacional de Sanidad Agraria (SENASA)/Ministerio de Agricultura (MINAG) para su empleo en el control de plagas agrícolas (RAAA, 2005). El Decreto Supremo $\mathrm{N}^{\circ} 016-2000-\mathrm{AG}$ en el Perú, que aprueba el reglamento para el registro y control de los plaguicidas químicos de uso agrícola, indica en su anexo 2 , que para el registro y la reevaluación de los plaguicidas deben realizarse estudios de efectos tóxicos sobre organismos no objetivos del control químico.

El metamidofos puede ocasionar efectos tóxicos en los organismos acuáticos, debido a su alta solubilidad en el agua (USEPA, 1998). Los organismos no destinatarios del control químico pueden ser usados para determinar si existen impactos negativos al emplear plaguicidas en el ambiente acuático (Iannacone y Alvariño, 2005a). Se han desarrollado diferentes protocolos de bioensayos para determinar el efecto de los plaguicidas sobre distintos componentes biológicos (Iannacone et al., 2000). Los parámetros de toxicidad más comúnmente empleados son la concentración letal media $\left(\mathrm{CL}_{50}\right)$, la concentración efectiva media $\left(\mathrm{CE}_{50}\right)$ y la concentración de inhibición media $\left(\mathrm{CI}_{50}\right)\left(\right.$ en $\left.\mathrm{mg} \mathrm{L}^{-1}\right)$.

Las especies de la familia Chironomidae son muy utilizadas en bioensayos para determinar el grado de toxicidad de diversas sustancias químicas en ambientes acuáticos, midiendo su sobrevivencia y otros efectos subletales (Iannacone et al., 2005). La lombriz roja, Chironomus calligraphus (Goeldi, 1905) (Diptera: Chironomidae), es una especie característica de los ambientes acuáticos naturales y de origen antropogénico del Perú; presenta como ventaja principal su abundante y permanente disponibilidad del material biológico utilizado, así como su importancia en las cadenas tróficas (Iannacone y Alvariño, 2005b). Además son fáciles de mantener en cultivos en condiciones de laboratorio, presentan ciclo corto de vida y se conoce que son sensibles a metales pesados y pesticidas (Iannacone et al., 2002b; 2005).

El erizo negro marino Tetrapygus niger Molina, 1782 (Echinodermata: Arbaciidae), es un invertebrado perteneciente al intertidal rocoso marino de Perú y Chile (Rodríguez, 2003). En esta especie se han realizado una serie de trabajos en fisiología y en biología molecular (Medina et al., 2001). Se han realizado bioensayos de fertilización y embrionación evaluando el efecto de diversas sustancias químicas en el agua y sedimentos en diferentes especies de erizos marinos: Arbacia spatuligera (Valenciennes, 1846), Paracentrotus lividus Lamarck, 1816, Psammechinus miliaris (Gmelin, 1778), Sphaerechinus granularis (Lamarck, 1816), Tripneustes gratilla (Linnaeus, 1758) (Larrain et al., 1999; Ghirardini et al., 2001; Coteur et al., 2003; Vásquez, 2003; De Nicola et al., 2004; Pesando et al., 2004; Bellas et al., 2005). Iannacone et al. (1999) evaluaron el efecto del cobre en la embrionación del erizo $T$. niger.

Los peces son extremadamente sensibles a la perturbación ambiental. Numerosos peces han sido propuestos como modelos biológicos para evaluar la ecotoxicidad de sustancias químicas contaminantes, como los alevines de truchas Oncorhynchus mykiss (Walbaum, 1792), Pimephales promelas (Murty, 1986), Lepomis macrochirus (Rafinesque, 1986), Carassius auratus (Jones, 1973), Leiostomus xanthurus (Lacepede, 1802) y Cyprinodon variegatus (Murty, 1986) y Cichlasoma dimerus (Heckel, 1840), Poecilia reticulata Peters, 1859, Cynopoecilus melanotaenia (Regan, 1912) (Iannacone y Alvariño, 1998; Iannacone et al., 1998; Arenzon et al., 2003).

El neón tetra Paracheirodon innesi (Rabout, 1940) (Osteichthyes: Characidae), es una de las especies más conocidas y buscadas por los acuaristas ama- 
zónicos, oscilando su tamaño entre 4 a 5 cm (González y Preest, 1999). En esta especie se ha evaluado el efecto de varios metales pesados y pesticidas (Tao et al., 1999, 2002; Iannacone et al., 2004).

La trucha arco iris Oncorhynchus mykiss (Osteichthyes: Salmonidae), es uno de los principales recursos hidrobiológicos de la actividad de acuicultura continental en el Perú, es una especie que no soporta las poluciones acuáticas y son muy sensibles a las contaminaciones orgánicas (Valenzuela et al., 2002). Es una de las especies más usadas en bioensayos para evaluar el impacto de diversas sustancias químicas en los ecosistemas dulceacuícolas (Wan et al., 2005; 2006).

El objetivo del presente trabajo fue evaluar el efecto ecotoxicológico de dos formulaciones de metamidofos de diferente categoría toxicológica [Monofos ${ }^{\circledR}$, categoría Ia (extremadamente peligroso) y Tamaron ${ }^{\circledR}$, categoría Ib (altamente peligroso)] sobre cuatro organismos no destinatarios de la biota animal acuática: la larva del insecto acuático $C$. calligraphus, los gametos del erizo de mar T. niger, y finalmente los peces $P$. innesi y $O$. mykiss, y a partir de estos resultados evaluar el riesgo ambiental acuático de este insecticida.

\section{MATERIALES Y MÉTODOS}

Metamidofos. Se usaron dos formulaciones de concentrado soluble (CS) de metamidofos $\left(\mathrm{C}_{2} \mathrm{H}_{8} \mathrm{NO}_{2} \mathrm{PS}, \mathrm{PM}=141,1\right)$ representativas del mercado nacional (Monofos ${ }^{\circledR}$ (Farmagro, Taiwan), Categoría Ia "extremadamente peligroso" a $600 \mathrm{~g}$ i.a. $\mathrm{L}^{-1}$ y Tamaron ${ }^{\circledR}$ (Bayer, Alemania), Categoría Ib "altamente peligroso" a $600 \mathrm{~g}$ i.a. L-1 (SENASA, 1995). El metamidofos, O, S-dimetilo fosforamidotioato, presenta una toxicidad aguda oral en ratas de $\mathrm{DL}_{50}=20 \mathrm{mg} \mathrm{kg}^{-1} \mathrm{y}$ una toxicidad aguda dérmica de $\mathrm{DL}_{50}=130 \mathrm{mg} \mathrm{kg}^{-1}$. Su $\log \mathrm{K}_{\mathrm{ow}}=-0,66$, su tiempo de vida media es de 6 días y su solubilidad en agua es de 1.000.000 (Sinclair y Boxall, 2002; Stoorvogel et al., 2003). Para los ensayos la sustancia química se disolvió al $1 \%$ en agua destilada $\left(\mathrm{pH}=7,2\right.$; conductividad específica $\left.=7 \mathrm{~S} \mathrm{~m}^{-1}\right)$. En los ensayos se aplicaron concentraciones de ingrediente activo (i.a.) en $\mathrm{mg} \mathrm{L}^{-1} \mathrm{y}$ con un factor de dilución generalmente de 0,5 . La dosis de aplicación de metamidofos para el control de plagas en agricultura es de $1,8 \mathrm{~g}$ i.a. $\mathrm{L}^{-1}$.

\section{Organismos no destinatarios \\ Chironomus calligraphus. Para cada ensayo se co-} lectaron masas de huevos de C. calligraphus procedentes de las lagunas secundarias de estabilización de Villa El Salvador, Lima, Perú, las que se mantuvieron en agua libre de cloro a $20 \pm 3{ }^{\circ} \mathrm{C}$ en el laboratorio. La obtención y cría estandarizada de Chironomus siguió las recomendaciones de Iannacone y Dale (1999). Las pruebas se efectuaron con larvas de primer estadío con menos de $24 \mathrm{~h}$ de edad; se colocaron 10 especímenes en cada uno de los envases de vidrio de $35 \mathrm{~mL}$, con un volumen final de $25 \mathrm{~mL}$. Se utilizó un diseño en bloques completos al azar (DBCA) con cuatro repeticiones y cinco concentraciones del insecticida y un control (Iannacone y Alvariño, 2000). Todas las diluciones se hicieron con agua libre de cloro, agregando tiosulfato de sodio. Se emplearon cinco concentraciones en orden creciente: 2,$98 ; 5,95 ; 11,9 ; 23,8$ y 47,5 mg i.a. $\mathrm{L}^{-1}$. La mortalidad se midió a las $48 \mathrm{~h}$ de exposición a ambos productos. Se consideraron muertas aquellas larvas que no efectuaron ningún movimiento al ser pinchadas con un alfiler entomológico, bajo observación con estereoscopio durante $15 \mathrm{~s}$. El protocolo empleado siguió a Iannacone et al. (2005). Cada bioensayo se realizó cinco veces con Tamarón y tres veces con Monofos con fin de determinar la variabilidad de los resultados.

Tetrapygus niger. Se siguió el protocolo propuesto por Iannacone et al. (1999) para A. spatuligera. Los especímenes de $T$. niger se colectaron de las playas Agua Dulce y Barranquito, ambas adjuntas al Terminal Pesquero de Chorrillos, Lima, Perú. La estimulación para la evaluación del esperma y de los óvulos se realizó inyectándole $\mathrm{KCl} 0,5 \mathrm{M}$. El esperma se colectó usando una jeringa descartable de $5 \mathrm{~mL}$ y se colocó en un tubo de vidrio de $10 \mathrm{~mL}$ con ausencia de agua de mar y sobre hielo hasta el inicio del bioensayo. Los óvulos se colectaron en tubos de centrífuga. Se preparó una solución de espermios a $5 \times 10^{7}$ células $\mathrm{mL}^{-1}$ empleando agua de mar Ultravioleta usando un hemocitómetro (Boeco ${ }^{\circledR}$, Neubauer, Germany) y 2.000 óvulos $\mathrm{mL}^{-1}$ empleando para el recuento la cámara de SedgwickRafter (Phycotech ${ }^{\circledR}$, Sedgwick-Rafter cell, Saint Joseph, Michigan, USA). El ensayo se realizó a una temperatura de $20 \pm 2{ }^{\circ} \mathrm{C}$. Para el bioensayo se emplearon tubos de centrífuga de $20 \mathrm{~mL}$, a los que se agregaron $100 \mu \mathrm{L}$ de la suspensión de espermios. Después de $1 \mathrm{~h}$, se le agregó $1 \mathrm{~mL}$ de la suspensión de óvulos. Se consideró como criterio de validez 
del bioensayo un $75 \%$ de fertilización en los controles después de 20 min de agregar la suspensión de óvulos. Se agregó $0,5 \mathrm{~mL}$ de formalina a cada tubo para conservar el material para una lectura posterior. Para evaluar el porcentaje de fertilización se transfirió $1 \mathrm{~mL}$ de cada tubo de prueba a una cámara de Sedgwick-Rafter. Se contabilizó el número de huevos fertilizados y no fertilizados, diferenciándolos por la ausencia de la membrana de fertilización. Se emplearon cinco concentraciones de metamidofos: 11,$875 ; 23,75 ; 47,5 ; 95$ y $190 \mathrm{mg}$ i.a. $\mathrm{L}^{-1}$.

Paracheirodon innesi. Adultos de "neón tetra" $P$. innesi, sin distinción de sexo, se obtuvieron de un acuario del distrito de Jesús María en Lima, Perú. Posteriormente, los peces se transportaron al laboratorio en un envase de plástico de $4 \mathrm{~L}$ de capacidad. Los adultos se colocaron dos semanas previas a las pruebas ecotoxicológicas, en un medio a base de una solución amortiguadora (Buffer-fosfato) $(\mathrm{pH}$ 7): $8,5 \mathrm{mg} \mathrm{L}^{-1}$ de $\mathrm{KH}_{2} \mathrm{PO}_{4}, 21,75 \mathrm{mg} \mathrm{L}^{-1}$ de $\mathrm{K}_{2} \mathrm{HPO}_{4}$, $33,4 \mathrm{mg} \mathrm{L}^{-1}$ de $\mathrm{Na}_{2} \mathrm{HPO}_{4} \cdot 7 \mathrm{H}_{2} \mathrm{O}$ y $1,7 \mathrm{mg} \mathrm{L}^{-1}$ de $\mathrm{NH}_{4} \mathrm{Cl}$. Además de otras sales como sulfato de magnesio $\left(\mathrm{MgSO}_{4} 7 \mathrm{H}_{2} \mathrm{O}\right) 22 \mathrm{mg} \mathrm{L}^{-1}$, cloruro de calcio $\left(\mathrm{CaCl}_{2}\right) 27,3 \mathrm{mg} \mathrm{L}^{-1}$ y $0,00025 \mathrm{mg} \mathrm{L}^{-1}$ de cloruro férrico $\left(\mathrm{FeCl}_{3} 6 \mathrm{H}_{2} \mathrm{O}\right)$ (Iannacone y Dale, 1999). Los peces se alimentaron semanalmente con alimento para peces en hojuelas (TetraMin, Tetramin Tropical Flakes, Buffalo, New York, USA), y con hojuelas de cereal (Cereal Leaves, Sigma, Saint Louis, Missouri, USA). La temperatura para el mantenimiento de los peces fue de $26 \pm 2{ }^{\circ} \mathrm{C}$. Los neones tetra usados en los bioensayos se extrajeron del cultivo a partir de la segunda semana de aclimatación. Los peces seleccionados presentaron una apariencia externa saludable para su uso en los ensayos toxicológicos. Las pruebas de toxicidad se realizaron con cuatro repeticiones, y cinco concentraciones más el control. Se emplearon cinco concentraciones: 11,$19 ; 23,8 ; 47,5 ; 95$ y $190 \mathrm{mg}$ i.a. $\mathrm{L}^{-1}$. Las lecturas definitivas de la pruebas ecotoxicológicas se realizaron a los $10 ; 20 ; 40 \mathrm{~min} ; 1 ; 2 ; 3 ; 6$; 12; 24; 48; 72 y 96 h de exposición. Los peces no se alimentaron durante los bioensayos. Se usaron 120 neones para cada prueba de toxicidad. Cada grupo de cinco neones se colocó al azar en recipientes plásticos circulares de $250 \mathrm{~mL}$ con las respectivas concentraciones y el control. Cada bioensayo se repitió tres veces para cada formulación del metamidofos. Se utilizaron tres parámetros como punto final de lectura: una letal: muerte (al tocar el pez con un estilete y si después de 10 s no realiza ningún movimiento), y dos subletales: inmovilización (al tocar el pez con un estilete y si después de $10 \mathrm{~s}$ sigue moviendo el opérculo), y nado extraño.

Oncorhynchus mykiss. Se utilizaron las instalaciones del Laboratorio de Sanidad del Centro Piscícola, El Ingenio $\left(11^{\circ} 52^{\prime}\right.$ lat. Sur, $75^{\circ} 15^{\prime}$ long. Oeste,). Dicho centro se encuentra ubicado en la provincia de Concepción, departamento de Junín, Perú, a una altitud de 3.510 m.s.n.m. Se utilizaron alevines de 15 a 20 días después de la absorción del saco vitelino de la trucha arco iris $O$. mykiss procedente del Centro Piscícola El Ingenio. Los alevines se obtuvieron del proceso de producción del cultivo intensivo de trucha, previa coordinación con el encargado del área de alevinaje. Estos alevines se encontraron bajo condiciones de iniciación de alimento artificial. En este bioensayo no fue necesaria una aclimatación previa, debido a que se utilizó la misma calidad de agua que se empleó en el cultivo intensivo de la trucha, cuyas características fueron: temperatura del agua $=12^{\circ} \mathrm{C}, \mathrm{pH}=7,1 \pm 0,2$; oxígeno disuelto $=7 \pm 0,1 \mathrm{mg} \mathrm{L}^{-1}$; alcalinidad $=$ $280 \mathrm{mg} \mathrm{L}^{-1}$ y dureza total $=174 \mathrm{mg} \mathrm{L}^{-1}$. El fotoperíodo fue 12:12. Durante todo el bioensayo no se proporcionó alimento a los alevines. Los bioensayos de carácter agudo y subletal tuvieron una duración de 24, 48, 72 y 96 h, con un recambio de agua a las $48 \mathrm{~h}$ en los primeros tres ensayos del plaguicida metamidofos, y sin recambio de agua en los dos bioensayos restantes. Cada envase empleado tuvo una capacidad de $4 \mathrm{~L}$. Las pruebas para los bioensayos estuvieron compuestas de un control y nueve concentraciones nominales. Para cada prueba se necesitó un total de 240 alevines, de 2,4 a 3,8 $\mathrm{cm}$ de longitud y en un número de 10 especímenes por unidad de experimentación. En cada unidad se colocaron 10 peces que se distribuyeron al azar en cada una de las cuatro repeticiones. Las lecturas de mortalidad se realizaron a las $24,48,72$ y 96 h de exposición.

La longitud de los alevines se midió con una regla graduada de $1 \mathrm{~mm}$. Estas longitudes siempre se tomaron al final de cada prueba en el caso de los alevines vivos; y en el caso de los alevines muertos, se tomaron cada $24 \mathrm{~h}$, es decir en el momento de hacer las lecturas de mortalidad. En cada uno de los cinco bioensayos no existieron diferencias entre las tallas (cm) de los alevines: 1) 3,36 $\pm 0,34$ $(2,6-4,2) ; 2) 2,72 \pm 0,21(2,4-3,3) ; 3) 2,85 \pm 0,15$ 
$(2,6-3,3)$; 4) $2,76 \pm 0,21(2,3-3,2) ;$ y 5) $2,79 \pm 0,18$ $(2,4-3,2)(\mathrm{F}=0,67, \mathrm{P}=0,43)$. Para el ensayo de mortalidad con metamidofos (sólo con la clase Ia) se emplearon nueve concentraciones de i.a. en forma creciente: 4,$86 ; 11,9 ; 12,16 ; 23,8 ; 30,4 ; 47,5$; 76 ; 95 , y $190 \mathrm{mg}$ i.a. L ${ }^{-1}$. Para el bioensayo de subletalidad (incremento de movimiento opercular) con metamidofos se emplearon cinco concentraciones de i.a. en forma creciente: 11,$9 ; 23,8 ; 47,5 ; 95$; y $190 \mathrm{mg}$ i.a. $\mathrm{L}^{-1}$.

Diseño experimental y tratamiento de datos. Las pruebas de toxicidad aguda para $C$. calligraphus, $P$. innesi y subletales para $T$. niger, $P$. innesis y $O$. mykiss, se evaluaron en cinco concentraciones más el control, con cuatro repeticiones, en un diseño en bloques completos al azar (DBCA) de 6 x 4. Sólo para el caso de las pruebas de toxicidad aguda para O. mykiss se realizaron los bioensayos empleando nueve concentraciones. En todos los casos, la eficacia de los tratamientos y las repeticiones se evaluaron a través de un análisis de varianza (ANDEVA) de dos vías, previa transformación de los datos a raíz cuadrada del arcoseno. En el caso de existir diferencias significativas entre los tratamientos (concentraciones) y las repeticiones se realizó la prueba de Tukey $(\mathrm{P}=0,05) . \mathrm{CL}_{50}, \mathrm{CE}_{50} \mathrm{y} \mathrm{CI}_{50}$ se calcularon usando el programa computarizado Pro- bit (USEPA, 1994). El modelo de regresión se verificó usando el estadístico Chi-cuadrado. Se empleó el ANDEVA para determinar las diferencias entre las tallas de los alevines de O. mykiss empleadas en los bioensayos. Se empleó el paquete estadístico SPSS, versión 12,00 (SPSS, 2003) para el cálculo de los estadísticos descriptivos e inferenciales.

Evaluación del riesgo ambiental (ERA). Se empleó esta técnica para determinar la naturaleza y magnitud del riesgo del metamidofos en ambas categorías toxicológicas (Ia y Ib), usando los escenarios más críticos y de peor exposición en el agua. Se siguió el protocolo propuesto por Iannacone y Alvariño (2005a).

\section{RESULTADOS}

El Cuadro 1 muestra mayores porcentajes de mortalidad y $\mathrm{CL}_{50}$ en C. calligraphus bajo la acción del metamidofos categoría Ia, que bajo la acción del metamidofos categoría $\mathrm{Ib}$. El valor de $\mathrm{CL}_{50}$ fue $241 \%$ más sensible en la categoría Ia que Ib. Un patrón opuesto se observó en el bioensayo de inhibición de la fertilización de $T$. niger, pues la $\mathrm{CI}_{50}$ del metamidofos categoría Ib fue $134 \%$ más sensible que la categoría Ia.

Cuadro 1. Efecto del metamidofos (Clase Ia y Ib) en el porcentaje de mortalidad de Chironomus calligraphus (Chironomidae) a $48 \mathrm{~h}$ de exposición y en el porcentaje de inhibición de la fertilización de Tetrapygus niger (Arbaciidae) a 1 h de exposición.

Table 1. Effect of methamidophos (Class Ia and Ib) on mortality percentage of Chironomus calligraphus (Chironomidae) at $48 \mathrm{~h}$ exposure and on fertility inhibition percentage of Tetrapygus niger (Arbaciidae) at $1 \mathrm{~h}$ exposure.

\begin{tabular}{|c|c|c|c|c|c|}
\hline \multicolumn{3}{|c|}{ Chironomus calligraphus } & \multicolumn{3}{|c|}{ Tetrapygus niger } \\
\hline $\begin{array}{c}\text { Concentración } \\
\left(\mathrm{mg} \text { i.a. } \mathrm{L}^{-1}\right)\end{array}$ & $\begin{array}{l}\text { Mortalidad } \\
(\%)^{1}\end{array}$ & $\begin{array}{l}\text { Mortalidad } \\
(\%)^{2}\end{array}$ & $\begin{array}{c}\text { Concentración } \\
\left(\mathrm{mg} \text { i.a. } \mathrm{L}^{-1}\right)\end{array}$ & $\begin{array}{c}\text { Inhibición } \\
\qquad \%)^{1}\end{array}$ & $\begin{array}{c}\text { Inhibición } \\
(\%)^{2}\end{array}$ \\
\hline Control & $1,8 \mathrm{a}$ & $0,5 \mathrm{a}$ & Control & $0 \mathrm{a}$ & $0 \mathrm{a}$ \\
\hline 2,98 & $76,8 \mathrm{~b}$ & $44,4 \mathrm{~b}$ & 11,875 & $9,6 \mathrm{ab}$ & $8,8 \mathrm{ab}$ \\
\hline 5,95 & $86,2 \mathrm{bc}$ & $53,7 \mathrm{~b}$ & 23,75 & $14,1 \mathrm{ab}$ & $12,4 \mathrm{ab}$ \\
\hline 11,9 & $94 \mathrm{c}$ & $62,7 \mathrm{~b}$ & 47,5 & $17,7 \mathrm{ab}$ & $16,6 \mathrm{ab}$ \\
\hline 23,8 & $100 \mathrm{c}$ & $77,9 \mathrm{~b}$ & 95 & $21,9 \mathrm{~b}$ & $31,4 \mathrm{~b}$ \\
\hline 47,5 & $100 \mathrm{c}$ & $79,7 \mathrm{~b}$ & 190 & $26,4 \mathrm{~b}$ & $31,6 \mathrm{~b}$ \\
\hline $\mathrm{F}$ & 110 & 11,68 & $\mathrm{~F}$ & 9,68 & 13,4 \\
\hline Sig. & 0,00 & 0,00 & Sig. & 0,00 & 0,00 \\
\hline $\mathrm{CL}_{50}$ & 1,32 & 4,50 & $\mathrm{CI}_{50}$ & 1.423 & 608,3 \\
\hline
\end{tabular}

Letras minúsculas iguales en una misma columna indican que los porcentajes de mortalidad son estadísticamente iguales según prueba de Tukey $(\mathrm{P}=0,05)$.

${ }^{1}$ metamidofos (Monofos ${ }^{\circledR}$, Clase Ia); ${ }^{2}$ metamidofos (Tamaron ${ }^{\circledR}$, Clase Ib).

$\mathrm{F}=$ estadístico de Fisher; Sig. = Significancia; $\mathrm{CL}_{50}$ : concentración letal media; $\mathrm{CI}_{50}$ : concentración de inhibición media. 
El efecto del metamidofos categoría Ia en el porcentaje de mortalidad de $P$. innesi entre $10 \mathrm{~min}$ a $96 \mathrm{~h}$ de exposición, indica que los efectos se empezaron a observar recién desde las $6 \mathrm{~h}$ de exposición. $\mathrm{La} \mathrm{CL}_{50}$ a $96 \mathrm{~h}$ fue $2.014 \%$ más sensible que a las 6 h de exposición (Cuadro 2). El mismo comportamiento se observó para los dos puntos subletales: inmovilización y nado extraño, pero en estos casos se observaron efectos desde las $3 \mathrm{~h}$ de exposición. La $\mathrm{CE}_{50}$ para la inmovilización de $P$. innesi a $96 \mathrm{~h}$ fue $1.620 \%$ más sensible que a las $3 \mathrm{~h}$ de exposición (Cuadro 3). $\mathrm{La} \mathrm{CE}_{50}$ para el nado extraño de $P$. innesi a $96 \mathrm{~h}$ fue $1.800 \%$ más sensible que a las 3 h de exposición (Cuadro 4).

Por otro lado, el efecto del metamidofos categoría Ib en el porcentaje de mortalidad de $P$. innesi entre 10 min a 96 h de exposición, indica que los efectos se empezaron a observar recién desde las $6 \mathrm{~h}$ de exposición. $\mathrm{La}_{\mathrm{CL}} \mathrm{L}_{50}$ a $96 \mathrm{~h}$ fue $1.834 \%$ más sensible que a las $12 \mathrm{~h}$ de exposición (Cuadro 5). El mismo comportamiento se observó para

Cuadro 2. Efecto del metamidofos (Clase Ia) en el porcentaje de mortalidad de Paracheirodon innesi (Characidae) de 10 min a 96 h de exposición.

Table 2. Effect of methamidophos (Class Ia) on mortality percentage of Paracheirodon innesi (Characidae) at 10 min to $96 \mathrm{~h}$ exposure.

\begin{tabular}{|c|c|c|c|c|c|c|c|c|c|c|c|c|}
\hline \multirow{3}{*}{$\begin{array}{l}\text { Concentr. } \\
\left(\mathrm{mg} \text { i.a. } \mathrm{L}^{-1}\right)\end{array}$} & \multicolumn{12}{|c|}{ Tiempo de exposición } \\
\hline & 10 & 20 & 40 & 1 & 2 & 3 & 6 & 12 & 24 & 48 & 72 & 96 \\
\hline & & $\min$ & & \multicolumn{9}{|c|}{$\mathbf{h}$} \\
\hline Control & 0 & 0 & 0 & 0 & 0 & 0 & $0 \mathrm{a}$ & $0 \mathrm{a}$ & $0 \mathrm{a}$ & $0 \mathrm{a}$ & $0 \mathrm{a}$ & $0 \mathrm{a}$ \\
\hline 11,9 & 0 & 0 & 0 & 0 & 0 & 0 & $0 \mathrm{a}$ & $0 \mathrm{a}$ & $1,6 \mathrm{a}$ & $1,6 \mathrm{a}$ & $6,6 \mathrm{a}$ & $30 \mathrm{~b}$ \\
\hline 23,8 & 0 & 0 & 0 & 0 & 0 & 0 & $0 \mathrm{a}$ & $1,6 \mathrm{a}$ & $1,6 \mathrm{a}$ & $5 a$ & $16,6 \mathrm{a}$ & $53,3 \mathrm{c}$ \\
\hline 47,5 & 0 & 0 & 0 & 0 & 0 & 0 & $0 \mathrm{a}$ & $0 \mathrm{a}$ & $8,3 \mathrm{a}$ & $18,3 \mathrm{a}$ & $50 \mathrm{~b}$ & $83,3 \mathrm{~d}$ \\
\hline 95 & 0 & 0 & 0 & 0 & 0 & 0 & $1,6 a b$ & $16,6 \mathrm{a}$ & $55 \mathrm{~b}$ & $68,3 \mathrm{~b}$ & $90 \mathrm{c}$ & $93,3 \mathrm{~d}$ \\
\hline 190 & 0 & 0 & 0 & 0 & 0 & 0 & $13,3 \mathrm{~b}$ & $55 \mathrm{~b}$ & $90 \mathrm{c}$ & $100 \mathrm{c}$ & $100 \mathrm{c}$ & $100 \mathrm{~d}$ \\
\hline $\mathrm{F}$ & ND & ND & ND & ND & ND & ND & 4,4 & 14,1 & 46,5 & 70,4 & 43,9 & 93,6 \\
\hline Sig. & ND & ND & ND & ND & ND & ND & 0,01 & 0,00 & 0,00 & 0,00 & 0,00 & 0,00 \\
\hline $\mathrm{CL}_{50}$ & ND & ND & ND & ND & ND & ND & 414 & 181 & 90,41 & 68,88 & 42,32 & 20,56 \\
\hline
\end{tabular}

Letras minúsculas iguales en una misma columna indican que los porcentajes de mortalidad son estadísticamente iguales según prueba de Tukey $(\mathrm{P}=0,05)$.

$\mathrm{F}=$ estadístico de Fisher; Sig. = significancia; $\mathrm{ND}=$ no determinado; Ia = metamidofos (Monofos $\left.{ }^{\circledR}, \mathrm{Clase} I \mathrm{I}\right) ; \mathrm{CL}_{50}$ : concentración letal media.

Cuadro 3. Efecto del metamidofos (Clase Ia) en el porcentaje de Paracheirodon innesi (Characidae) inmóviles de 10 min a 96 h de exposición.

Table 3. Effect of methamidophos (Class Ia) on immobilization percentage of Paracheirodon innesi (Characidae) at $10 \mathrm{~min}$ to $96 \mathrm{~h}$ exposure.

\begin{tabular}{|c|c|c|c|c|c|c|c|c|c|c|c|c|}
\hline \multirow{3}{*}{$\begin{array}{l}\text { Concentr. } \\
\left(\mathrm{mg} \text { i.a. } \mathrm{L}^{-1}\right)\end{array}$} & \multicolumn{12}{|c|}{ Tiempo de exposición } \\
\hline & 10 & 20 & 40 & 1 & 2 & 3 & 6 & 12 & 24 & 48 & 72 & 96 \\
\hline & & $\min$ & & \multicolumn{9}{|c|}{$\mathbf{h}$} \\
\hline Control & 0 & 0 & 0 & 0 & 0 & $0 \mathrm{a}$ & $0 \mathrm{a}$ & $0 \mathrm{a}$ & $0 \mathrm{a}$ & $0 \mathrm{a}$ & $0 \mathrm{a}$ & $0 \mathrm{a}$ \\
\hline 11,9 & 0 & 0 & 0 & 0 & 0 & $0 \mathrm{a}$ & $0 \mathrm{a}$ & $0 \mathrm{a}$ & $1,6 \mathrm{a}$ & $3,3 \mathrm{ab}$ & $15 \mathrm{a}$ & $40 \mathrm{~b}$ \\
\hline 23,8 & 0 & 0 & 0 & 0 & 0 & $0 \mathrm{a}$ & $0 \mathrm{a}$ & $3,3 \mathrm{a}$ & $3,3 \mathrm{a}$ & $10 \mathrm{ab}$ & $50 \mathrm{~b}$ & $66,6 \mathrm{c}$ \\
\hline 47,5 & 0 & 0 & 0 & 0 & 0 & $0 \mathrm{a}$ & $0 \mathrm{a}$ & $1,6 \mathrm{a}$ & $26,6 \mathrm{a}$ & $35 \mathrm{~b}$ & $78,3 \mathrm{c}$ & $88,3 \mathrm{c}$ \\
\hline 95 & 0 & 0 & 0 & 0 & 0 & $0 \mathrm{a}$ & $1,6 \mathrm{a}$ & $30 \mathrm{~b}$ & $63,3 \mathrm{~b}$ & $81,6 \mathrm{c}$ & $93,3 \mathrm{c}$ & $96,6 \mathrm{~cd}$ \\
\hline 190 & 0 & 0 & 0 & 0 & 0 & $1,6 \mathrm{a}$ & $25 \mathrm{~b}$ & $65 \mathrm{c}$ & $90 \mathrm{~b}$ & $100 \mathrm{c}$ & $100 \mathrm{~d}$ & $100 \mathrm{~d}$ \\
\hline $\mathrm{F}$ & ND & ND & ND & ND & ND & 1,0 & 22 & 57,6 & 32,7 & 39,3 & 98,7 & 68,6 \\
\hline Sig. & ND & ND & ND & ND & ND & 0,46 & 0,00 & 0,00 & 0,00 & 0,00 & 0,00 & 0,00 \\
\hline $\mathrm{CE}_{50}$ & ND & ND & ND & ND & ND & ND & 265 & 145 & 75,15 & 53,60 & 25,62 & 15,41 \\
\hline
\end{tabular}

Letras minúsculas iguales en una misma columna indican que los porcentajes de mortalidad son estadísticamente iguales según prueba de Tukey $(\mathrm{P}=0,05)$.

$\mathrm{F}=$ estadístico de Fisher; Sig. = significancia; $\mathrm{ND}=$ no determinado; $\mathrm{Ia}=$ metamidofos $\left(\right.$ Monofos $\left.{ }^{\circledR}, \mathrm{Clase} \mathrm{Ia}\right) ; \mathrm{CE}_{50}=$ concentración efectiva media. 
los dos puntos subletales: inmovilización y nado extraño, pero en estos caso se observaron efectos desde las $3 \mathrm{~h}$ de exposición. La $\mathrm{CE}_{50}$ para la inmovilización de $P$. innesi a 96 h fue $3.675 \%$ más sensible que a las $6 \mathrm{~h}$ de exposición (Cuadro 6). La $\mathrm{CE}_{50}$ para el nado extraño de $P$. innesi a 96 $\mathrm{h}$ fue $9.333 \%$ más sensible que a las $3 \mathrm{~h}$ de exposición (Cuadro 7). $\mathrm{La} \mathrm{CL}_{50}$ a $96 \mathrm{~h}$ fue $103 \%$ más sensible en el metamidofos categoría Ia que Ib (Cuadros 2 y 5). En adición, la $\mathrm{CE}_{50}$ para la inmovilización a 96 h fue $89 \%$ más sensible en el metamidofos categoría Ia que Ib (Cuadros 3 y 6). La $\mathrm{CE}_{50}$ para el nado extraño a $96 \mathrm{~h}$ fue $82 \%$ más sensible en el metamidofos categoría Ia que Ib (Cuadros 4 y 7 ).

En el metamidofos categoría Ia, la $\mathrm{CE}_{50}$ para el nado extraño a $96 \mathrm{~h}$ fue $128 \%$ más sensible que la $\mathrm{CL}_{50}$ a 96 h. El mismo comportamiento se observó en el metamidofos categoría $\mathrm{Ib}$, donde la $\mathrm{CE}_{50}$ para el nado extraño a $96 \mathrm{~h}$ fue $105 \%$ más sensible que la $\mathrm{CL}_{50}$ a $96 \mathrm{~h}$. En ambas formulaciones del metamido-

Cuadro 4. Efecto del metamidofos (Clase Ia) en el porcentaje de Paracheirodon innesi (Characidae) con nado extraño de 10 min a 96 h de exposición.

Table 4. Effect of methamidophos (Class Ia) on stranger swimming percentage of Paracheirodon innesi (Characidae) at $10 \mathrm{~min}$ to $96 \mathrm{~h}$ exposure.

\begin{tabular}{|c|c|c|c|c|c|c|c|c|c|c|c|c|}
\hline \multirow{3}{*}{$\begin{array}{l}\text { Concentr. } \\
\left(\mathrm{mg} \text { i.a. } \mathrm{L}^{-1}\right)\end{array}$} & \multicolumn{12}{|c|}{ Tiempo de exposición } \\
\hline & 10 & 20 & 40 & 1 & 2 & 3 & 6 & 12 & 24 & 48 & 72 & 96 \\
\hline & \multicolumn{3}{|c|}{$\min$} & \multicolumn{9}{|c|}{$\mathbf{h}$} \\
\hline Control & 0 & 0 & 0 & 0 & 0 & $0 \mathrm{a}$ & $0 \mathrm{a}$ & $0 \mathrm{a}$ & $0 \mathrm{a}$ & $0 \mathrm{a}$ & $0 \mathrm{a}$ & $0 \mathrm{a}$ \\
\hline 11,9 & 0 & 0 & 0 & 0 & 0 & $0 \mathrm{a}$ & $0 \mathrm{a}$ & $0 \mathrm{a}$ & $6,6 \mathrm{a}$ & $21,6 \mathrm{~b}$ & $36,6 \mathrm{~b}$ & $65 \mathrm{~b}$ \\
\hline 23,8 & 0 & 0 & 0 & 0 & 0 & $0 \mathrm{a}$ & $0 \mathrm{a}$ & $3,3 \mathrm{a}$ & $35 \mathrm{ab}$ & $58,3 \mathrm{c}$ & $78,3 \mathrm{c}$ & $85 \mathrm{c}$ \\
\hline 47,5 & 0 & 0 & 0 & 0 & 0 & $0 \mathrm{a}$ & $0 \mathrm{a}$ & $1,6 \mathrm{a}$ & $50 \mathrm{bc}$ & $83,3 \mathrm{~d}$ & $95 \mathrm{~cd}$ & $98,3 \mathrm{~d}$ \\
\hline 95 & 0 & 0 & 0 & 0 & 0 & $0 \mathrm{a}$ & $6,6 \mathrm{a}$ & $31,6 \mathrm{~b}$ & $86,6 \mathrm{~cd}$ & $98,3 \mathrm{~d}$ & $100 \mathrm{~d}$ & $100 \mathrm{~d}$ \\
\hline 190 & 0 & 0 & 0 & 0 & 0 & $8,3 \mathrm{~b}$ & $60 \mathrm{~b}$ & $71,6 \mathrm{c}$ & $96,6 \mathrm{~d}$ & $100 \mathrm{~d}$ & 100 & $100 \mathrm{~d}$ \\
\hline $\mathrm{F}$ & ND & ND & ND & ND & ND & 25 & 125 & 49 & 24,6 & 134 & 126 & 822 \\
\hline Sig. & ND & ND & ND & ND & ND & 0,00 & 0,00 & 0,00 & 0,00 & 0,00 & 0,00 & 0,00 \\
\hline $\mathrm{CE}_{50}$ & ND & ND & ND & ND & ND & ND & 171 & 131 & 39,7 & 21,23 & 14,72 & 9,00 \\
\hline
\end{tabular}

Letras minúsculas iguales en una misma columna indican que los porcentajes de mortalidad son estadísticamente iguales según prueba de Tukey $(\mathrm{P}=0,05)$.

$\mathrm{F}=$ estadístico de Fisher; Sig. = significancia; $\mathrm{ND}=$ no determinado; Ia = metamidofos $\left(\right.$ Monofos ${ }^{\circledR}$, Clase Ia); $\mathrm{CE}_{50}:$ concentración efectiva media.

Cuadro 5. Efecto del metamidofos (Clase Ib) en el porcentaje de mortalidad de Paracheirodon innesi (Characidae) de $10 \mathrm{~min}$ a 96 h de exposición.

Table 5. Effect of methamidophos (Class Ib) on mortality percentage of Paracheirodon innesi (Characidae) at 10 min to $96 \mathrm{~h}$ exposure.

\begin{tabular}{|c|c|c|c|c|c|c|c|c|c|c|c|c|}
\hline \multirow{2}{*}{$\begin{array}{l}\text { Concentr. } \\
\left(\mathrm{mg} \text { i.a. } \mathrm{L}^{-1}\right)\end{array}$} & \multicolumn{12}{|c|}{ Tiempo de exposición } \\
\hline & 10 & 20 & 40 & 1 & 2 & 3 & 6 & 12 & 24 & 48 & 72 & 96 \\
\hline & \multicolumn{3}{|c|}{$\min$} & \multicolumn{9}{|c|}{$\mathbf{h}$} \\
\hline Control & 0 & 0 & 0 & 0 & 0 & $0 \mathrm{a}$ & $0 \mathrm{a}$ & $0 \mathrm{a}$ & $0 \mathrm{a}$ & $0 \mathrm{a}$ & $0 \mathrm{a}$ & $0 \mathrm{a}$ \\
\hline 11,9 & 0 & 0 & 0 & 0 & 0 & $0 \mathrm{a}$ & $0 \mathrm{a}$ & $1,6 \mathrm{a}$ & $3,3 \mathrm{a}$ & $12,5 \mathrm{a}$ & $30 \mathrm{a}$ & $61,6 \mathrm{~b}$ \\
\hline 23,8 & 0 & 0 & 0 & 0 & 0 & $0 \mathrm{a}$ & $0 \mathrm{a}$ & $0 \mathrm{a}$ & $1,6 \mathrm{a}$ & $25 \mathrm{ab}$ & $55 \mathrm{ab}$ & $81,6 \mathrm{bc}$ \\
\hline 47,5 & 0 & 0 & 0 & 0 & 0 & $3,3 \mathrm{a}$ & $10 \mathrm{a}$ & $16,6 \mathrm{a}$ & $48,3 \mathrm{~b}$ & $87,5 \mathrm{bc}$ & $98,3 \mathrm{~b}$ & $100 \mathrm{c}$ \\
\hline 95 & 0 & 0 & 0 & 0 & 0 & $0 \mathrm{a}$ & $1,6 \mathrm{a}$ & $31,6 \mathrm{a}$ & $86,6 \mathrm{c}$ & $100 \mathrm{c}$ & $100 \mathrm{~b}$ & $100 \mathrm{c}$ \\
\hline 190 & 0 & 0 & 0 & 0 & 0 & $0 \mathrm{a}$ & $15 \mathrm{a}$ & $45 \mathrm{a}$ & $100 \mathrm{~d}$ & $100 \mathrm{c}$ & $100 \mathrm{~b}$ & $100 \mathrm{c}$ \\
\hline $\mathrm{F}$ & ND & ND & ND & ND & ND & 1,00 & 1,19 & 2,18 & 340 & 16,05 & 10,54 & 53,75 \\
\hline Sig. & ND & ND & ND & ND & ND & 0,46 & 0,37 & 0,12 & 0,00 & 0,002 & 0,00 & 0,00 \\
\hline $\mathrm{CL}_{50}$ & ND & ND & ND & ND & ND & ND & ND & 196 & 50,55 & 27,41 & 18,27 & 10,13 \\
\hline
\end{tabular}

Letras minúsculas iguales en una misma columna indican que los porcentajes de mortalidad son estadísticamente iguales según prueba de Tukey $(\mathrm{P}=0,05)$.

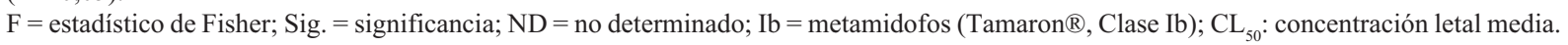


fos para $P$. innesi, la secuencia de sensibilización de punto final de lectura fue: nado extraño $>$ inmovilización $>$ mortalidad.

El efecto del metamidofos categoría Ib sobre los alevines de $O$. mykiss, indica un aumento de la mortalidad y del incremento del movimiento opercular con la concentración y con el tiempo de exposición (Cuadros 8 y 9). La $\mathrm{CL}_{50}$ a 96 h fue $214 \%$ más sensible que a las $24 \mathrm{~h}$ de exposición (Cuadro 8). No se observaron diferencias marcadas entre la $\mathrm{CL}_{50}$ a
48; 72; y 96 h de exposición. La CE ${ }_{50}$ para el incremento del movimiento opercular de O. mykiss a 96 $\mathrm{h}$ fue $241 \%$ más sensible que a las $24 \mathrm{~h}$ de exposición (Cuadro 9). $\mathrm{La} \mathrm{CE}_{50}$ para el incremento del movimiento opercular de O. mykiss a 96 h fue $19 \%$ más sensible que la $\mathrm{CL}_{50} 96 \mathrm{~h}$ de exposición (Cuadros 8 y 9 ).

La secuencia de sensibilidad al metamidofos en ambas formulaciones en términos de $\mathrm{CL}(\mathrm{E} / \mathrm{I})_{50}$ fue: C. calligraphus $>O$. mykiss $\approx$ P. innesi $>$ T. niger.

Cuadro 6. Efecto del metamidofos (Clase Ib) en el porcentaje de Paracheirodon innesi (Characidae) inmóviles de 10 min a 96 h de exposición.

Table 6. Effect of methamidophos (Clase Ib) on the immobilization percentage of Paracheirodon innesi (Characidae) at 10 min to $96 \mathrm{~h}$ exposure.

\begin{tabular}{|c|c|c|c|c|c|c|c|c|c|c|c|c|}
\hline \multirow{3}{*}{$\begin{array}{l}\text { Concentr. } \\
\left(\mathrm{mg} \text { i.a. } \mathrm{L}^{-1}\right)\end{array}$} & \multicolumn{12}{|c|}{ Tiempo de exposición } \\
\hline & 10 & 20 & 40 & 1 & 2 & 3 & 6 & 12 & 24 & 48 & 72 & 96 \\
\hline & \multicolumn{3}{|c|}{$\min$} & \multicolumn{8}{|c|}{$\mathbf{h}$} & \\
\hline Control & 0 & 0 & 0 & 0 & $0 \mathrm{a}$ & $0 \mathrm{a}$ & $0 \mathrm{a}$ & $0 \mathrm{a}$ & $0 \mathrm{a}$ & $0 \mathrm{a}$ & $0 \mathrm{a}$ & $0 \mathrm{a}$ \\
\hline 11,9 & 0 & 0 & 0 & 0 & $0 \mathrm{a}$ & $0 \mathrm{a}$ & $0 \mathrm{a}$ & $3,3 \mathrm{a}$ & $5 \mathrm{a}$ & $25 \mathrm{a}$ & $45 \mathrm{ab}$ & $71,6 \mathrm{~b}$ \\
\hline 23,8 & 0 & 0 & 0 & 0 & $0 \mathrm{a}$ & $0 \mathrm{a}$ & $3,3 \mathrm{a}$ & $3,3 \mathrm{a}$ & $8,3 \mathrm{a}$ & $45 \mathrm{ab}$ & $71,6 \mathrm{bc}$ & $93,3 \mathrm{c}$ \\
\hline 47,5 & 0 & 0 & 0 & 0 & $1,6 \mathrm{a}$ & $3,3 \mathrm{a}$ & $10 \mathrm{a}$ & $28,3 \mathrm{ab}$ & $81,6 \mathrm{~b}$ & $92,5 \mathrm{~b}$ & $100 \mathrm{c}$ & $100 \mathrm{c}$ \\
\hline 95 & 0 & 0 & 0 & 0 & $0 \mathrm{a}$ & $0 \mathrm{a}$ & $11,6 \mathrm{a}$ & $53,3 \mathrm{bc}$ & $93,3 \mathrm{~b}$ & $100 \mathrm{~b}$ & $100 \mathrm{c}$ & $100 \mathrm{c}$ \\
\hline 190 & 0 & 0 & 0 & 0 & $16,6 \mathrm{a}$ & $33,3 \mathrm{a}$ & $38,3 \mathrm{a}$ & $78,3 \mathrm{c}$ & $100 \mathrm{~b}$ & $100 \mathrm{~b}$ & $100 \mathrm{c}$ & $100 \mathrm{c}$ \\
\hline $\mathrm{F}$ & ND & ND & ND & ND & 0,96 & 0,96 & 1,13 & 11,89 & 79,67 & 15,27 & 17,08 & 82,29 \\
\hline Sig. & ND & ND & ND & ND & 0,47 & 0,47 & 0,39 & 0,00 & 0,00 & 0,002 & 0,00 & 0,00 \\
\hline $\mathrm{CE}_{50}$ & ND & ND & ND & ND & ND & ND & 308 & 90,14 & 36,56 & 21,07 & 13,88 & 8,16 \\
\hline
\end{tabular}

Letras minúsculas iguales en una misma columna indican que los porcentajes de mortalidad son estadísticamente iguales según prueba de Tukey $(\mathrm{P}=0,05)$.

$\mathrm{F}=$ estadístico de Fisher; Sig. = significancia; $\mathrm{ND}=$ no determinado; $\mathrm{Ib}=$ metamidofos (Tamaron $\left.{ }^{\circ}, \mathrm{Clase} \mathrm{Ib}\right) ; \mathrm{CE}_{50}$ : concentración efectiva media.

Cuadro 7. Efecto del metamidofos (Clase Ib) en el porcentaje de Paracheirodon innesi (Characidae) con nado extraño de 10 min a 96 h de exposición.

Table 7. Effect of methamidophos (Class Ib) on strange swimming percentage of Paracheirodon innesi (Characidae) at $10 \mathrm{~min}$ to $96 \mathrm{~h}$ exposure.

\begin{tabular}{|c|c|c|c|c|c|c|c|c|c|c|c|c|}
\hline \multirow{2}{*}{$\begin{array}{l}\text { Concentr. } \\
\left(\mathrm{mg} \text { i.a. } \mathrm{L}^{-1}\right)\end{array}$} & \multicolumn{12}{|c|}{ Tiempo de exposición } \\
\hline & 10 & 20 & 40 & 1 & 2 & 3 & 6 & 12 & 24 & 48 & 72 & 96 \\
\hline & \multicolumn{3}{|c|}{$\min$} & \multicolumn{9}{|c|}{$\mathbf{h}$} \\
\hline Control & 0 & 0 & 0 & 0 & $0 \mathrm{a}$ & $0 \mathrm{a}$ & $0 \mathrm{a}$ & $0 \mathrm{a}$ & $0 \mathrm{a}$ & $0 \mathrm{a}$ & $0 \mathrm{a}$ & 0 \\
\hline 11,9 & 0 & 0 & 0 & 0 & $0 \mathrm{a}$ & $0 \mathrm{a}$ & $0 \mathrm{a}$ & $8,3 \mathrm{a}$ & $26,6 \mathrm{~b}$ & $47,5 \mathrm{~b}$ & $86,6 \mathrm{~b}$ & 100 \\
\hline 23,8 & 0 & 0 & 0 & 0 & $0 \mathrm{a}$ & $0 \mathrm{a}$ & $5 \mathrm{a}$ & $8,3 \mathrm{a}$ & $41,6 \mathrm{c}$ & $82,5 \mathrm{bc}$ & $96,6 \mathrm{~b}$ & 100 \\
\hline 47,5 & 0 & 0 & 0 & 0 & $1,6 \mathrm{a}$ & $3,3 \mathrm{a}$ & $33,3 \mathrm{ab}$ & $83,3 \mathrm{~b}$ & $96,6 \mathrm{~d}$ & $97,5 \mathrm{c}$ & $100 \mathrm{~b}$ & 100 \\
\hline 95 & 0 & 0 & 0 & 0 & $0 \mathrm{a}$ & $13,3 \mathrm{ab}$ & $45 \mathrm{~b}$ & $91,6 \mathrm{~b}$ & $96,6 \mathrm{~d}$ & $100 \mathrm{c}$ & $100 \mathrm{~b}$ & 100 \\
\hline 190 & 0 & 0 & 0 & 0 & $5 \mathrm{a}$ & $20 \mathrm{~b}$ & $88,3 \mathrm{c}$ & $98,3 \mathrm{~b}$ & $100 \mathrm{~d}$ & $100 \mathrm{c}$ & $100 \mathrm{~b}$ & 100 \\
\hline $\mathrm{F}$ & ND & ND & ND & ND & 0,88 & 6,06 & 23,13 & 50,65 & 576 & 30,52 & 171 & ND \\
\hline Sig. & ND & ND & ND & ND & 0,52 & 0,005 & 0,00 & 0,00 & 0,00 & 0,00 & 0,00 & ND \\
\hline $\mathrm{CE}_{50}$ & ND & ND & ND & ND & ND & 466 & 83,85 & 36,39 & 20,96 & 12,41 & 4,94 & $<4,94$ \\
\hline
\end{tabular}

Letras minúsculas iguales en una misma columna indican que los porcentajes de mortalidad son estadísticamente iguales según prueba de Tukey $(\mathrm{P}=0,05)$.

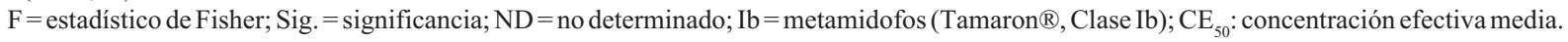


Siendo C. calligraphus 1.078 y 135 veces más sensible que T. niger en términos de CL(E/I)s, para la clase Ia y Ib, respectivamente (Cuadros 1 y 10). La ERA del metamidofos categoría Ia y Ib en el ambiente acuático, mostró alto riesgo para las cua- tro especies en el ambiente acuático, pues los cuocientes de riesgo (CR) fluctuaron entre 4,2 y 4.545 para el metamidofos categoría Ia y entre 9,8 y 1.333 para la categoría Ib (Cuadro 10).

Cuadro 8. Efecto del metamidofos (Clase Ib) en el porcentaje de mortalidad de Oncorhynchus mykiss (Salmonidae) de 24 a 96 h de exposición.

Table 8. Effect of methamidophos (Class Ib) on the mortality percentage of Oncorhynchus mykiss (Salmonidae) at 24 to $96 \mathrm{~h}$ exposure.

\begin{tabular}{ccccc}
\hline \multirow{2}{*}{$\begin{array}{c}\text { Concentr. } \\
\left.\text { (mg i.a. } \mathbf{L}^{-1}\right)\end{array}$} & \multicolumn{4}{c}{ Tiempo de exposición (h) } \\
\cline { 2 - 5 } & $\mathbf{2 4}$ & $\mathbf{4 8}$ & $\mathbf{7 2}$ & $\mathbf{9 6}$ \\
\hline 0 & $0 \mathrm{a}$ & $0 \mathrm{a}$ & $0 \mathrm{a}$ & $0 \mathrm{a}$ \\
4,8 & $0 \mathrm{a}$ & $0 \mathrm{a}$ & $1,7 \mathrm{a}$ & $2,5 \mathrm{a}$ \\
11,90 & $0 \mathrm{a}$ & $2,5 \mathrm{a}$ & $7,5 \mathrm{a}$ & $16,3 \mathrm{a}$ \\
12,10 & $0 \mathrm{a}$ & $0,0 \mathrm{a}$ & $6,7 \mathrm{a}$ & $19,1 \mathrm{a}$ \\
23,80 & $7,5 \mathrm{a}$ & $43,8 \mathrm{~b}$ & $57,5 \mathrm{~b}$ & $58,8 \mathrm{~b}$ \\
30,40 & $6,6 \mathrm{a}$ & $41,7 \mathrm{~b}$ & $65,0 \mathrm{~b}$ & $82,5 \mathrm{c}$ \\
47,50 & $46,3 \mathrm{~b}$ & $96,3 \mathrm{c}$ & $100 \mathrm{c}$ & $100 \mathrm{c}$ \\
76 & $56,7 \mathrm{~b}$ & $95,8 \mathrm{c}$ & $100 \mathrm{c}$ & $100 \mathrm{c}$ \\
95 & $92,5 \mathrm{c}$ & $100 \mathrm{c}$ & $100 \mathrm{c}$ & $100 \mathrm{c}$ \\
190 & $100 \mathrm{c}$ & $100 \mathrm{c}$ & $100 \mathrm{c}$ & $100 \mathrm{c}$ \\
CL & 60,11 & 31,08 & 23,83 & 19,12 \\
Límite inferior & 45,63 & 22,71 & 15,73 & 13,39 \\
Límite superior & 83,03 & 46,89 & 32,30 & 23,43 \\
F & $79,49-231$ & $109-377$ & $96,35-293$ & $128-351$ \\
Sig. & 0,00 & 0,00 & 0,00 & 0,00 \\
\hline
\end{tabular}

Letras minúsculas iguales en una misma columna indican que los porcentajes de mortalidad son estadísticamente iguales según prueba de Tukey $(\mathrm{P}=0,05)$.

$\mathrm{F}=$ estadístico de Fisher; Sig. = significancia; $\mathrm{Ib}=$ metamidofos $($ Tamaron $\mathbb{}$, Clase $\mathrm{Ib}) ; \mathrm{CL}_{50}$ : concentración letal media.

Cuadro 9. Efecto del metamidofos (Clase Ib) en el porcentaje de incremento de movimiento opercular de Oncorhynchus mykiss (Salmonidae) de 24 h a 96 h de exposición.

Table 9. Effect of methamidophos (Class Ib) on the increment of opercula movement percentage of Oncorhynchus mykiss (Salmonidae) at 24 to $96 \mathrm{~h}$ exposure.

\begin{tabular}{ccccc}
\hline $\begin{array}{c}\text { Concentr. } \\
\left(\mathbf{m g} \text { i.a. } \mathbf{L}^{-1}\right)\end{array}$ & \multicolumn{4}{c}{ Tiempo de exposición $\mathbf{( h )}$} \\
\hline 0 & $0 \mathrm{a}$ & $\mathbf{4 8}$ & $\mathbf{7 2}$ & $\mathbf{9 6}$ \\
11,9 & $0 \mathrm{a}$ & $0,8 \mathrm{a}$ & $0 \mathrm{a}$ & $0 \mathrm{a}$ \\
23,8 & $0,8 \mathrm{a}$ & $2,5 \mathrm{a}$ & $14,2 \mathrm{a}$ & $5 \mathrm{a}$ \\
47,5 & $13,3 \mathrm{a}$ & $50,8 \mathrm{~b}$ & $75 \mathrm{~b}$ & $90 \mathrm{c}$ \\
95,0 & $70 \mathrm{~b}$ & $96,7 \mathrm{c}$ & $99,2 \mathrm{c}$ & $99,2 \mathrm{c}$ \\
190 & $100 \mathrm{c}$ & $100 \mathrm{c}$ & $100 \mathrm{c}$ & $100 \mathrm{c}$ \\
$\mathrm{CE}_{50}$ & 55,03 & 30,00 & 20,63 & 16,13 \\
Límite inferior & 50,05 & 14,7 & 18,71 & 11,54 \\
Límite superior & 60,51 & 61,0 & 22,83 & 22,49 \\
F & 48,3 & 55,6 & 62,1 & 56,8 \\
Sig. & 0,00 & 0,00 & 0,00 & 0,00 \\
\hline
\end{tabular}

Letras minúsculas iguales en una misma columna indican que los porcentajes de mortalidad son estadísticamente iguales según prueba de Tukey $(\mathrm{P}=0,05)$.

$\mathrm{F}=$ estadístico de Fisher; Sig. = significancia; $\mathrm{Ib}=$ metamidofos $\left(\right.$ Tamaron ${ }^{\circledR}$, Clase $\left.\mathrm{Ib}\right) ; \mathrm{CE}_{50}$ : concentración efectiva media. 
Cuadro 10. Resumen de la Evaluación de Riesgos Ambientales (ERA) del metamidofos (Clases Ia y Ib) con organismos no destinatarios.

Table 10. Summary of Environmental Risk Aquatic Assessment (ERA) of methamidophos (Classes Ia and Ib) with non-target organisms.

\begin{tabular}{|c|c|c|c|c|c|c|c|}
\hline Especie & Estimador & Tiempo & $\begin{array}{c}\text { Toxicidad } \\
\left(\mathrm{mg} \text { i.a. } \mathrm{L}^{-1}\right)\end{array}$ & $\begin{array}{l}\text { Exposición } \\
\left(\mathrm{mg} \text { i.a. } \mathrm{L}^{-1}\right)\end{array}$ & $\mathbf{C R}$ & LOC & Riesgo \\
\hline \multicolumn{8}{|l|}{ Metamidofos (Ia) } \\
\hline Chironomus calligraphus & $\mathrm{CL}_{50}$ & $48 \mathrm{~h}$ & 1,32 & 6.000 & 4.545 & 0,5 & Sí \\
\hline Tetrapygus niger & $\mathrm{CI}_{50}^{50}$ & $15 \mathrm{~min}$ & 1.423 & 6.000 & 4,2 & 0,5 & Sí \\
\hline Paracheirodon innesi (mortalidad) & $\mathrm{CL}_{50}$ & $96 \mathrm{~h}$ & 20,56 & 6.000 & 291 & 0,5 & Sí \\
\hline Paracheirodon innesi (inmoviliz.) & $\mathrm{CE}_{50}^{50}$ & $96 \mathrm{~h}$ & 15,43 & 6.000 & 388 & 0,5 & Sí \\
\hline Paracheirodon innesi (nado extraño) & $\mathrm{CE}_{50}^{50}$ & $96 \mathrm{~h}$ & 9,01 & 6.000 & 665 & 0,5 & Sí \\
\hline \multicolumn{8}{|l|}{ Metamidofos (Ib) } \\
\hline Chironomus calligraphus & $\mathrm{CL}_{50}$ & $48 \mathrm{~h}$ & 4,50 & 6.000 & 1.333 & 0,5 & Sí \\
\hline Tetrapygus niger & $\mathrm{CI}_{50}^{50}$ & $15 \mathrm{~min}$ & 608,3 & 6.000 & 9,8 & 0,5 & Sí \\
\hline Oncorhynchus mykiss & $\mathrm{CL}_{50}^{50}$ & $96 \mathrm{~h}$ & 19,12 & 6.000 & 313 & 0,5 & Sí \\
\hline Oncorhynchus mykiss (nado extraño) & $\mathrm{CE}_{50}^{50}$ & $96 \mathrm{~h}$ & 16,13 & 6.000 & 372 & 0,5 & Sí \\
\hline Paracheirodon innesi (mortalidad) & $\mathrm{CL}_{50}^{50}$ & $96 \mathrm{~h}$ & 10,13 & 6.000 & 592 & 0,5 & Sí \\
\hline Paracheirodon innesi (inmovilización) & $\mathrm{CE}_{50}^{50}$ & $96 \mathrm{~h}$ & 8,16 & 6.000 & 735 & 0,5 & Sí \\
\hline Paracheirodon innesi (nado extraño) & $\mathrm{CE}_{50}^{50}$ & $96 \mathrm{~h}$ & $<4,94$ & 6.000 & 1.214 & 0,5 & Sí \\
\hline
\end{tabular}

Exposición $=$ concentración efectiva ambiental $\mathrm{CR}=$ cuociente de riesgo $=$ Exposición $/$ Toxicidad $; \mathrm{LOC}=$ nivel critico; $\mathrm{CL}_{50}$ : concentración letal media; $\mathrm{CI}_{50}$ : concentración de inhibición media; $\mathrm{CE}_{50}$ : concentración efectiva media; $\mathrm{Ia}=$ metamidofos $\left(\right.$ Monofos ${ }^{\circledR}$, Clase Ia); Ib = metamidofos (Tamaron ${ }^{\circledR}$, Clase $\left.\mathrm{Ib}\right)$.

\section{DISCUSIÓN}

El potencial del uso de organismos biológicos como bioindicadores en ensayos de ecotoxicidad está ampliamente documentado (Karabay y Oguz, 2005). Su principal utilidad en ecotoxicología es la de mostrar los efectos del tóxico a nivel individual, y así inferir los efectos a nivel poblacional y comunitario (Iannacone y Alvariño, 2005a). El metamidofos, en sus dos formulaciones, categorías Ia y Ib, mostró efectos de alto riesgo en las cuatro especies analizadas, dos invertebrados (el artrópodo dulceacuícola $C$. calligraphus y el equinodermo marino T. niger) y dos peces vertebrados dulceacuícolas (O. mykiss, de aguas frías y P. innesi, de aguas tropicales).

El bioensayo de mortalidad con el díptero C. calligraphus mostró mayor sensibilidad para ambas formulaciones en comparación a las otras tres especies evaluadas (Cuadro 10). En comparación con otros invertebrados acuáticos dulceacuícolas y marinos, se encontró que $C$. calligraphus ocupó el quinto lugar de sensibilidad al metamidofos en comparación a siete especies. Siendo la secuencia en orden de mayor a menor sensibilidad: Macrobrachium rosenbergii (De Man, 1879) $\left(\mathrm{CL}_{50}=0,000042\right.$ $\left.\mathrm{mg} \mathrm{L}{ }^{-1}\right)>$ Penaeus stylirostris Stimpson, $1874\left(\mathrm{CL}_{50}\right.$ $\left.=0,00016 \mathrm{mg} \mathrm{L}^{-1}\right)>$ Daphnia magna $($ Strauss, 1820) $\left(\mathrm{CL}_{50}=0,026 \mathrm{mg} \mathrm{L}^{-1}\right.$ a $48 \mathrm{~h}$ de exposición $)>$ Americamysis bahia (Molenock, 1969) $\left(\mathrm{CL}_{50}=1,05 \mathrm{mg}\right.$ $\left.\mathrm{L}^{-1}\right)>C$. calligraphus $\left(\mathrm{CL}_{50}=1,32-4,5 \mathrm{mg} \mathrm{L}^{-1}\right)>$ Crassostrea virginia (Gmelin, 1791) $\left(\mathrm{CL}_{50}=36 \mathrm{mg}\right.$ $\left.\mathrm{L}^{-1}\right)>$ T. niger $\left(\mathrm{CI}_{50}=608,3-1.423 \mathrm{mg} \mathrm{L}^{-1}\right)$ (USEPA, 1998).

Iannacone y Alvariño (2005a) al evaluar la selectividad del cartap en el ambiente acuático, encontraron que de cuatro especies evaluadas, $C$. calligraphus ocupó el tercer lugar. En el langostino Litopennaeus vannamei Boone, 1931, se han encontrado efectos subletales del metamidofos, observándose que las alteraciones en el comportamiento fueron más sensibles que la inhibición de la acetilcolinesterasa. En cambio la tasa de alimentación como punto final de lectura, no mostró diferencias significativas en comparación con el control (García de la Parra et al., 2006). En nuestro caso, las respuestas subletales de alteraciones en el comportamiento como nado extraño para $P$. innesi y de incremento del movimiento opercular para $O$. mykiss, fueron respuestas más sensibles que la mortalidad en ambos casos. En comparación con otros peces dulceacuícolas y marinos se encontró que O. mykiss y 
P. innesi ocuparon el segundo y tercer lugar de sensibilidad al metamidofos, en comparación a seis especies de peces. Siendo la secuencia en orden de mayor a menor sensibilidad: $C$. variegatus $\left(\mathrm{CL}_{50}=\right.$ $5,6 \mathrm{mg} \mathrm{L}^{-1}$ a $\left.96 \mathrm{~h}\right)>$ P. innesi $\left(\mathrm{CL}_{50}=10,13\right.$ a 20,56 $\mathrm{mg} \mathrm{L}^{-1}$ a $\left.96 \mathrm{~h}\right)>$ O. mykiss $\left(\mathrm{CL}_{50}=19,12 \mathrm{mg} \mathrm{L}^{-1} \mathrm{a}\right.$ $96 \mathrm{~h})>$ L. macrochirus $\left(\mathrm{CL}_{50}=31 \mathrm{mg} \mathrm{L}^{-1}\right.$ a $\left.96 \mathrm{~h}\right)>$ Oreochromis niloticus Linnaeus, $1766\left(\mathrm{CL}_{50}=\right.$ 29,20 $\mathrm{mg} \mathrm{L}^{-1}$ a $96 \mathrm{~h}$ ) > Cyprinus carpio (Linnaeus, 1758) $\left(\mathrm{CL}_{50}=68 \mathrm{mg} \mathrm{L}^{-1}\right.$ a $\left.96 \mathrm{~h}\right)>$ Hypophthalmichthys molitrix (Valenciennes, 1844) $\left(\mathrm{CL}_{50}=158,5\right.$ $\mathrm{mg} \mathrm{L}^{-1}$ a 48 h) (Wu et al., 1984; Dileanis et al., 1996; USEPA, 1998).

Aunque se esperaba que, en todos los casos, la formulación de metamidofos Ia presentaría los mayores efectos toxicológicos en los bioensayos realizados en comparación con la Ib, sólo se observó esto en C. calligraphus (Cuadro 10). Por todas estas razones, el uso del plaguicida metamidofos en sus categorías toxicológicas Ia y Ib, a pesar de sus aparentes efectos positivos en la producción agrícola, debe ser motivo de preocupación continua en el Perú por sus impactos en el ambiente acuático (Stoorvogel et al., 2003). Por otro lado, en nuestro medio son muy comunes las aplicaciones de metamidofos al doble de las concentraciones recomendadas, y de dos a cuatro aplicaciones continuas para el control de las plagas por el agricultor (observación personal). Este hecho originaría un mayor impacto en la fauna benéfica aérea, al incrementar los niveles de exposición a las mismas. En el presente trabajo, el análisis ecotoxicológico de cuatro especies animales con diferentes nichos ecológicos para determinar la selectividad del metamidofos, podría contribuir a tomar medidas más idóneas para su empleo en el manejo integrado de plagas.

\section{CONCLUSIONES}

La secuencia de sensibilidad al metamidofos en ambas formulaciones en términos de $\mathrm{CL}(\mathrm{E} / \mathrm{I})_{50}$ fue: $C$. calligraphus $>O$. mykiss $\approx P$. innesi $>T$. niger.

Los dos efectos subletales en $P$. innesi: inmovilización y nado extraño, y finalmente, en $O$. mykiss: incremento de movimiento opercular, fueron más sensibles que los efectos de mortalidad.

Los cuocientes de riesgo (CR) indicaron un alto riesgo del metamidofos en el ambiente acuático.

\section{RECONOCIMIENTOS}

A la Red de Acción en Alternativas al uso de Agroquímicos (RAAA) por el financiamiento de la presente investigación durante el 2003-2004. Este trabajo fue presentado en varias partes a cuatro eventos: 1) en el III Congreso Peruano de Ecología, 26 al 30 de septiembre del 2004, Arequipa, Perú; 2) en el VIII Congresso Brasileiro de EcotoxicologiaSETAC Brasil, 17 - 20 de octubre del 2004, Florianopolis, Santa Catarina, Brasil; 3) en la XLVI Convención Nacional de Entomología, 07 al 11 noviembre del 2004, Arequipa, Perú; y 4) en el VII Congreso SETAC LA, 16 al 20 de octubre de 2005, Santiago de Chile, Chile.

\section{LITERATURA CITADA}

Arenzon, A., R.F. Pinto, P. Colombo, and M.T. RayaRodríguez. 2003. Assessment of the freshwater annual fish Cynopoecilus melanotaenia as a toxicity test organism using three referente substancies. Environ. Toxicol. Chem. 22:2188-2190.

Bellas, J., R. Beiras, M. Marino-Balsa, and N. Fernández. 2005. Toxicity of organic compounds to marine invertebrate embryos and larvae: a comparison between the sea urchin embryogenesis bioassay and alternative test species. Ecotoxicol. 14:337-353.

Bouchard, M., G. Carrier, R.C. Brunet, P. Dumas, and N. Noisel. 2006. Biological monitoring of exposure to organophosphorus insecticides in a group of horticultural greenhouse workers. Ann. Hyg. 50:505515 .
Coteur, G., P. Gosselin, P. Wantier, Y. Chambost-Manciet, B. Danis, P. Pernet, et al. 2003. Echinoderms as bioindicators, bioassays, and impact assessment tools of sediment-associated metals and PCBs in the North Sea. Arch. Environ. Contam. Toxicol. 45:190-202.

De Nicola, E., M. Gallo, M. Iaccarino, S. Meric, R. Oral, T. Russo, et al. 2004. Hormetic versus toxic effects of vegetable tannin in a multitest study. Arch. Environ. Contam. Toxicol. 46:336-344.

Dileanis, P.D., S.E. Schwarzbach, and J. Bennett. 1996. Detailed study of water quality, bottom sediment, and biota asociated with irrigation drainage in the Klamath basin, California and Oregon, 1990-92. WaterResources Investigations Report 9 5-4232. 68 p. U.S. Geological Survey, Sacramento, California, USA. 
Evaristo, A., and G.C. Baptista. 2002. Dislodgeable residues of metamidophos in staked tomatoes. Sci. Agri. (Piracicaba, Braz.) 59:469-473.

García-de la Parra, L.M., J.C. Bautista-Covarrubias, N. Rivera-de la Rosa, M. Betancourt-Lozano, and L. Guilhermino. 2006. Effects of methamidophos on acetylcholinesterase activity, behavior, and feeding rate of the white shrimp (Litopenaeus vannamei). Ecotoxicol. Environ. Saf. 65:372-280.

Ghirardini, A.V., A.A. Novelli, B. Likar, G. Pojana, P.F. Ghetti, and A. Marcomini. 2001. Sperm cell toxicity test using sea urchin Paracentrotus lividus Lamarck (Echinodermata: Echinoidea): sensitivity and discriminatory ability toward anionic and nonionic surfactants. Environ. Toxicol. Chem. 20:644-651.

González, R.J., and M.R. Preest. 1999. Ionoregulatory specializations for exceptional tolerance of ion-poor, acidic waters in the neon tetra (Paracheirodon innesi). Physiol. Biochem. Zool. 72:156-163.

He, F., S. Chen, X. Tang, W. Gan, B. Tao, and B. Wen. 2002. Biological monitoring of combined exposure to organophosphates and pyrethroids. Toxicol. Lett. 134:119-124.

Hernández, M.E., F.J. Egea, M.L. Castro, M. Moreno, and J.L. Martínez. 2002. Residues of methamidophos, malathion, and methiocarb in greenhouses crops. J. Agric. Food Chem. 50:1172-1177.

Iannacone, J., y L. Alvariño. 1998. Ecotoxicidad aguda del zinc sobre el "guppy" Poecilia reticulata. Wiñay Yachay 2(3):67-74.

Iannacone, J., y L. Alvariño. 2000. Chironomus calligraphus Goeldi y Moina macrocopa (Sars) como herramientas ecotoxicológicas para la evaluación del lindano y clorpirifos. Bol. Soc. Biol. Concepción (Chile) 71:33-39.

Iannacone, J., y L. Alvariño. 2005a. Selectividad del insecticida cartap empleando bioensayo con organismos no destinatarios. Ecol. Appl. 4:91-104.

Iannacone, J., y L. Alvariño. 2005b. Efecto ecotoxicológico del cadmio en la eclosión de huevos de Chironomus calligraphus Goeldi 1905 (Diptera: Chironomidae). Revista de Ciencias 2:7-17.

Iannacone, J., L. Alvariño, y C. Caballero. 2002a. Empleo del caracol de agua dulce Physa venustula como herramienta ecotoxicológica para la evaluación de riesgo ambientales por plaguicidas. Agric. Téc. (Chile) 62:212-225.

Iannacone, J., L. Alvariño, C. Caballero, y J. Sánchez. 2000. Cuatro ensayos ecotoxicológicos para evaluar lindano y clorpirifos. Gayana 64:139-146.

Iannacone, J., L. Alvariño, y W. Dale. 1998. Pruebas ecotoxicológicas como herramientas para la evaluación del impacto ambiental. Bol. Lima (Perú) 113:53-68.
Iannacone, J., L. Alvariño, M. Dionisio, y J. Sánchez. 1999. Efecto del $\mathrm{Cu}^{2+}$ en la embrionación del erizo negro Tetrapygus niger (Molina) y en la fertilización del erizo marrón, Arbacia spatuligera (Valenciennes) (Echinodermatha). Bol. Soc. Quim. Perú 65:182-190.

Iannacone, J., L. Alvariño, y J. Mansilla. 2002b. Actividad insecticida de cuatro extractos botánicos sobre larvas de los mosquitos Culex quinquefasciatus (Diptera: Culicidae) y Chironomus calligraphus (Diptera: Chironomidae). Wiñay Yachay 6:56-71.

Iannacone, J., A. Arrascue, and M. Cárdenas. 2005. Assessment of ecotoxicity of sediments of Aruri River and Junin Lake (Perú) employing Escherichia coli and Chironomus calligraphus. Braz. J. Toxicol. 18:27-41.

Iannacone, J., y W. Dale. 1999. Protocolo de bioensayos ecotoxicológicos para evaluar metales pesados contaminantes de agua dulce con Chironomus calligraphus (Diptera: Chironomidae) y Moina macrocopa (Crustacea: Cladocera), en el río Rímac, Lima, Perú. Rev. Per. Entomol. 41:111-120.

Iannacone, J., R. Onofre, y O. Huanqui. 2004. Efecto ecotoxicológico del cartap sobre Poecilia reticulata "Guppy” y Paracheirodon innesi"Neón Tetra". p. 43. In Iannacone, J. (ed.). Programa y Resúmenes. I Congreso Nacional Estudiantil en Ciencias Ambientales, Lima. 19 al 23 de abril del 2004. Universidad Nacional Federico Villarreal, Lima, Perú.

Ismail, B.S., U.B. Cheah, A.O. Enoma, K.Y. Lum, and Z. Malik. 2002. Movement and persistence of methamidophos in vegetable agroecosystem. Bull. Environ. Contam. Toxicol. 69:444-451.

Karabay, N.U., and M.G. Oguz. 2005. Cytogenetic and genotoxic effects of the insecticides, imidacloprid and methamidophos. Genet. Mol. Res. 4:653-662.

Larraín, A., A. Riveros, J. Silva, and E. Bay-Schmith. 1999. Toxicity of metals and pesticides using the sperm cell bioassay with the sea urchin Arbacia spatuligera. Bull. Environ. Contam. Toxicol. 62:749757.

Medina, R., R. Paredes, M. Puchi, M. Imschenetzky, and M. Montecino. 2001. Developmentally-regulated interaction of a transcription factor complex containing $\mathrm{CDP} /$ cut with the early histone $\mathrm{H} 3$ gene promoter of the sea urchin Tetrapygus niger is associated with changes in chromatin structure and gene expression. Gene 272:237-248.

Pesando, D., S. Robert, P. Huitorel, E. Gutknecht, L. Pereira, J.P. Girard, and B. Ciapa. 2004. Effects of methoxychlor, dieldrin and lindane on sea urchin fertilization and early development. Aquat. Toxicol. 66:225-239.

Prieto, A., D. Molero, G. González, I. Buscema, G. Ettiene, and D. Medina. 2002. Persistence of methamidophos, diazinon, and malathion in tomatoes. Bull. Environ. Contam. Toxicol. 69:479-485. 
RAAA. 2005. Plaguicidas Ia, Ib en el Perú: Campaña para la prohibición y restricción de los plaguicidas extremadamente y altamente peligrosos. $12 \mathrm{p}$. Red de Acción en Alternativas al uso de Agroquímicos (RAAA), Lima, Perú.

Recena, M.C., E.D. Caldas, D.X. Pires, and E.R. Pontes. 2006. Pesticides exposure in Culturama, Brazilknowledge, attitudes, and practices. Environ. Res. 102:230-236.

Rodríguez, S.R. 2003. Consumption of drift kelp by intertidal populations of the sea urchin Tetrapygus niger on the central Chilean coast: possible consequences at different ecological levels. Mar. Ecol. Prog. Ser.251:141-151.

SENASA. 1995. Compendio de plaguicidas agrícolas y sustancias afines registrados en el Servicio Nacional de Sanidad Agraria (SENASA). 170 p. Ministerio de Agricultura, Lima, Perú.

Sinclair, C.J., and A.B.A. Boxall. 2002. Assessment of the environmental properties and effects of pesticide transformation products. 55 p. Final Report. Cranfield Centre for EcoChemistry. Cranfield University, Silsoe, UK.

Sosa-Gómez, D.R., I.C. Corso, and L. Morales. 2001. Insecticide resistance to Endosulfan, Monocrotophos and Metamidophos in the neotropical brown stink bug, Euschistus heros (F.). Neotropical Entomol. 30:317320.

SPSS. 2003. Statistical package for the social sciences. Base 12.0 User's guide. 368 p. SPSS Inc., Chicago, Illinois, USA.

Stoorvogel, J., R. Jaramillo, R. Merino, y S. Kosten. 2003. Plaguicidas en el medio ambiente. Capítulo 3. p. 4969. In D. Yanggen, C. Crissman, y P. Espinosa (eds.). Los plaguicidas: Impactos en producción, salud y medio ambiente en Carchi, Ecuador. Centro Internacional de la Papa, Instituto Nacional Autónomo de Investigaciones Agropecuarias. Ed. Abya-Yala, Quito, Ecuador.

Tao, S., T. Liang, J. Cao, R.W. Dawson, and C. Liu. 1999. Synergistic effect of copper and lead uptake by fish. Ecotoxicol. Environ. Saf. 44:190-195.

Tao, S., A. Long, B. Pan, F. Xu, and R. Dawson. 2002. Uptake of copper complexed to EDTA, diaminoethane, oxalic acid, or tartaric acid by neon tetras (Paracheirodon innesi). Ecotoxicol. Environ. Saf. 53:317-322.
USEPA. 1994. User's guide: Probit Program version 1.5. U.S. Environmental Protection Agency (USEPA). Ecological Monitoring Research Division, Cincinatti, Ohio, USA.

USEPA. 1998. EFED Methamidophos: Revision of EFED risk assessment for the reregistration eligibility decision (RED). Document to include registrant's comments. 73 p. United States Environmental Protection Agency (USEPA). Office of Prevention, Pesticides and Toxic Substances, Washington DC, USA.

Valenzuela, A., K. Alveal, and E. Tarifeño. 2002. Respuesta hematológica de truchas (Oncorhynchus mykiss Walbaum 1792) a estrés hipóxico agudo: serie roja. Gayana 66:255-261.

Vásquez, L.C. 2003. Effect of sperm cell density on measured toxicity from the sea urchin Tripneustes gratilla fertilization bioassay. Environ. Toxicol. Chem. 22:2191-2194.

Wan, M.T., C. Buday, G. Schroeder, J. Kuo, and J. Pasternak. 2006. Toxicity to Daphnia magna, Hyalella azteca, Oncorhynchus kisutch, Oncorhynchus mykiss, Oncorhynchus tshawytscha, and Rana catesbeiana of atrazine, metolachlor, simazine, and their formulated products. Bull. Environ. Contam. Toxicol. 76:52-58.

Wan, M.T., J.N. Kuo, C. Buday, G. Schroeder, G. Van Aggelen, and J. Pasternak. 2005. Toxicity of alphabeta-, (alpha + beta)-endosulfan and their formulated and degradation products to Daphnia magna, Hyalella azteca, Oncorhynchus mykiss, Oncorhynchus kisutch, and biological implications in streams. Environ. Toxicol. Chem. 24:1146-1154.

White, L.M., W.R. Ernst, G. Julien, C. Garron, and M. Leger. 2006. Ambient air concentrations of pesticides used in potato cultivation in Prince Edward Island, Canada. Pest. Manage. Sci. 62:126-136.

Wu, M.L., J.F. Deng, W.J. Tsai, J. Ger, S.S. Wong, and H.P. Li. 2001. Food poisoning due to methamidophoscontaminated vegetables. J. Toxicol. Clin. Toxicol. 39:333-336.

Wu, Y., X. Shu, J. Ying, Y. Yang, and J. Wu. 1984. Toxic effects of methamidophos on Grass Carp (Ctenopharynagodon idellus), Silver Carp (Hypophthalmichthys molitrix) and Nile Tilapia (Tilapia nilotica). Huanjing Kexue 5:1-5. 